\title{
Does the implicit outcomes expectancies shape learning and memory
} processes?

Carmona, Isabel; Mari-Beffa, Paloma; Estevez, A.F.

\section{Cognition}

DOI:

10.1016/j.cognition.2019.04.007

Published: 01/08/2019

Peer reviewed version

Cyswllt i'r cyhoeddiad / Link to publication

Dyfyniad o'r fersiwn a gyhoeddwyd / Citation for published version (APA):

Carmona, I., Mari-Beffa, P., \& Estevez, A. F. (2019). Does the implicit outcomes expectancies shape learning and memory processes? Cognition, 189, 181-187.

https://doi.org/10.1016/j.cognition.2019.04.007

\footnotetext{
Hawliau Cyffredinol / General rights

Copyright and moral rights for the publications made accessible in the public portal are retained by the authors and/or other copyright owners and it is a condition of accessing publications that users recognise and abide by the legal requirements associated with these rights.

- Users may download and print one copy of any publication from the public portal for the purpose of private study or research.

- You may not further distribute the material or use it for any profit-making activity or commercial gain

- You may freely distribute the URL identifying the publication in the public portal ?
}

Take down policy

If you believe that this document breaches copyright please contact us providing details, and we will remove access to the work immediately and investigate your claim. 
Does the implicit outcomes expectancies shape learning and memory processes?

Isabel Carmona ${ }^{1}$, Paloma Marí-Beffa ${ }^{2}$, and Angeles F. Estévez ${ }^{1,3^{*}}$

${ }^{1}$ Department of Psychology, Universidad de Almería, Spain

${ }^{2}$ School of Psychology, Bangor University, UK

${ }^{3}$ CERNEP Research Center, Universidad de Almería, Spain

* Correspondence:

Angeles F. Estévez

CERNEP Research Center

Universidad de Almería

04120 Almería, Spain

Phone number +34950214626

e-mail: mafernan@ual.es 
2 Does the explicit or implicit knowledge about the consequences of our choices shape

3 learning and memory processes? This seems to be the case according to previous studies

4 demonstrating improvements in learning and retention of symbolic relations and in

5 visuospatial recognition memory when each correct choice is reinforced with its own

6 unique and explicit outcome (the differential outcomes procedure, DOP). In the present

7 study, we aim to extend these findings by exploring the impact of the DOP under

8 conditions of non-conscious processing. To test for this, both the outcomes (Experiment

9 1A) and the sample stimuli (Experiment 1B) were presented under subliminal (non-

10 conscious) and supraliminal conditions in a delayed visual recognition memory task.

11 Results from both experiments showed a better visual recognition memory when

12 participants were trained with the DOP regardless the awareness of the outcomes or

13 even of the stimuli used for training. To our knowledge, this is the first demonstration

14 that the DOP can be effective under unconscious conditions. This finding is discussed in

15 the light of the two-memory systems model developed by Savage and colleagues to

16 explain the beneficial effects observed on learning and memory when differential

17 outcomes are applied.

19 Keywords: implicit processes, differential outcomes procedure, visual recognition memory 
Does the implicit outcomes expectancies shape learning and memory processes? We are continually making choices throughout our lives, choices that are usually followed by different consequences. For example, when crossing the road, the green light coincides with cars stopping allowing you to cross the road safely; on the contrary, the red light could be paired with cars passing, making road crossing a riskier option. In such situations, could the explicit or implicit knowledge of the consequences of our choices shape the way we learn and memorize information about them? This is a crucial question that has been indirectly and only partially addressed by research investigating the effect of administering differential (or specific) outcomes versus non-differential (or random) outcomes in discriminative learning tasks, and, more recently, in working memory.

The simple manipulation of administering differential outcomes, paring a unique outcome with each target stimulus or each correct stimulus-response sequence, is known as the differential outcomes procedure (DOP). To better understand this, let us consider a group of participants having to perform a delayed facial recognition task. That is, they have to remember faces that they have just seen (e.g., a man with a black beard, and a man with red hair and a moustache) and respond after a delay by selecting them among a group of distractor faces. When the DOP is applied, the correct recognition of each face is followed by a specific outcome. For example, participants only get the feedback "well done" when they correctly identify the face of the man with a black beard. Next, if the face is now the man with red hair and a moustache, the phrase "fantastic" will appear exclusively paired with it. By contrast, under the nondifferential outcomes condition (NOP) there is not a predetermined and specific association between the faces and the outcomes. Therefore, participants receive a random phrase (e.g. "well done" or "fantastic") following their correct responses. 
56 Previous studies have demonstrated that the DOP is effective in optimizing

57 discriminative learning and visuospatial recognition memory in healthy people (e.g.,

58 Easton, 2004; Esteban, Vivas, Fuentes, \& Estévez, 2015; Estévez et al., 2007; López-

59 Crespo, Plaza, Fuentes, \& Estévez, 2009; Martínez, Estévez, Fuentes, \& Overmier,

60 2009; Miller, Waugh, \& Chambers, 2002; Mok \& Overmier, 2007; Molina, Plaza,

61 Fuentes, \& Estévez, 2015; Plaza, Estévez, López-Crespo, \& Fuentes, 2011; Plaza,

62 Molina, Fuentes, \& Estévez, 2018). The DOP also helps to improve the same cognitive

63 processes in populations with neurocognitive deficits (e.g., Carmona, Vivas, \& Estévez,

64 2019; Esteban, Plaza, López-Crespo, Vivas, \& Estévez, 2014; Estévez, Fuentes,

65 Overmier, \& González, 2003; Hochhalter, Sweeney, Bakke, Holub, \& Overmier, 2000;

66 Joseph, Overmier, \& Thompson, 1997; Martínez et al., 2012; Plaza, López-Crespo,

67 Antúnez, Fuentes, \& Estévez, 2012). Taken together, these findings indicate that the

68 DOP is a very promising, economic, and effective technique; which can be applied in

69 diverse settings, such as schools and mental health clinics.

70 It is worth noting that in all the aforementioned studies, the target stimuli as well

71 as the outcomes were supraliminally presented thus allowing its explicit processing.

72 Accordingly, when participants assigned to the DOP condition have been asked which outcome was paired with each discriminative stimulus following the training, they have responded correctly (see Maki, Overmier, Delos, \& Gutman, 1995). Thus, although the main goal of these studies has been specifically to explore the potential benefits of the

76 DOP on learning and memory in different populations, it could be said that, based on

77 their procedures, both processes are affected by the explicit or conscious knowledge of 78 the outcomes. However, no studies have addressed whether the unconscious knowledge 79 of the consequences of our choices would equally influence learning and memory. If so, 
80 this finding would have relevant applied implications with strong significance for

81 current theories.

82 To our knowledge, very little research has been done on the cognitive and neural

83 mechanisms underlying the DOP, particularly in humans. The most accepted

84 explanation with the strongest empirical support is the one proposed by Savage and

85 colleages (e.g., Savage, Pitking, \& Careri, 1999; Savage, 2001; Savage, \& Ramos,

86 2009) based on animal research. This theory, the two-memory systems model, suggests

87 that there are two different memory systems: (i) prospective, activated when the DOP is

88 applied; and (ii) retrospective, activated when the outcomes are not specific of the

89 associations to be learned or of the target stimuli (the NOP condition). Continuing with

90 the previous example, an implicit association between the target stimulus (e.g., a man

91 with a black beard) and its unique outcome (e.g., the phrase "well done") is established

92 under the DOP condition. A Pavlovian association like this is responsible for creating

93 unique reward expectancies (or implicit-prospective memory representations of the

94 forthcoming outcome). This prospective memory system is largely implicit and has

95 been linked to the functioning of glutamatergic pathways by Savage and colleagues.

96 After several training trials, the presentation of the target stimulus automatically

97 activates the expectancy of its unique outcome. This expectancy (or Pavolovian

98 conditioned anticipatory state) has discriminative or functional stimulus-like properties

99 and, therefore, can be used to guide the selection of the correct response independent of

100 target stimulus information (e.g., Overmier, Savage, \& Sweeney, 1999; Savage,

101 Buzzetti, \& Ramirez, 2004). Noteworthy, expectancies are also functionally different

102 thant rememberign a past event. For instance, they are more persistent than retrospective

103 memories (e.g., Overmier, Savage, \& Sweeney, 1999) and are unaffected by

104 hippocampal lesions (e.g., Savage et al., 2004). A theoretical assumption of the two- 
memory systems model is that the Pavolovian-induced expectancy of the forthcoming

106 outcome is maintained throughout the delay interval in delayed matching-to-sample

107 tasks. In other words, the unique expectancy of the phrase "well done" facilitates the

108 subsequent recognition of the face of a man with a black beard after the delay, without a

109 representation of such stimulus being activated and maintained in working memory. By

110 contrast, when the NOP is applied, there is no specific information available about the

111 forthcoming outcomes so participants would have to remember the target stimulus they

112 have just seen (e.g., the face of a man with a black beard) during the delay to correctly

113 solve the task. This process would require a retrospective memory system associated

114 with the hippocampus that is dependent on Acetylcholine.

115 There has been only one study exploring the basic mechanisms underlying the

116 DOP in humans using functional magnetic resonance imaging (fMRI), and the results

117 seem to support the two memory systems model. Mok, Thomas, Lungu, and Overmier

118 (2009), using a delayed matching-to-sample task with young adults, observed that

119 separate brain regions are recruited when differential or non-differential outcomes are

120 used. Namely, when DOP was used, the lateral posterior parietal cortex, and more

121 specifically the angular gyrus, was activated during the blank delay between the offset

122 of the sample stimulus and the onset of the choice stimuli. By contrast, when the NOP

123 was applied, greater hippocampal (medial temporal lobe) activation was observed.

124 Furthermore, in the DOP condition, areas specific to the sensorial processing of the

125 outcome (auditory vs. visual), were also activated during this delay. These findings

126 were used to suggest that the expectation of an outcome, elicited by the sample

127 stimulus, may indeed be represented in prospective memory. In an extension of this

128 study, Mok (2012) argued that short-term retrospective (NOP) and prospective (DOP)

129 memory processes (i) are mediated by two different subsets of the default brain network 
130 (the medial temporal lobe would be involved in monitoring what has just happened -the

131 cue or sample stimulus- whereas the lateral parietal lobe would be implicated in

132 prospective processing of what is forthcoming -the outcome-) and (ii) might be

133 spontaneously engaged not requiring a deliberate and effortful activation.

134 Despite current support to the idea that the DOP stimulates implicit memory

135 systems, and thus is largely unaffected by consciousness and explicit expectations, this

136 aspect has remained a theoretical assumption and has never been tested. The present

137 study will provide first evidence on the role of awareness in the DOP with important

138 implications for theoretical models and its applications in humans. To do so, both the

139 outcomes (Experiment 1A) and the sample stimuli (Experiment 1B) will be presented

140 under subliminal (non-conscious) and supraliminal (conscious) conditions in a delayed

141 visual recognition memory task. Subliminal presentation aims to eliminate the

142 subjective visibility of the stimuli by masking and displaying them for a few

143 milliseconds (e.g., Breitmeyer \& Ogmen, 2006). The provided information is therefore

144 inaccessible to consciousness and it cannot be reported (Dehaene, Changeux, Naccache,

145 Sackur, \& Sergent, 2006), although their processing still can be boosted by increasing

146 attention to them (Dehaene et al., 2006). By contrast, supraliminal presentation allows

147 the subjective visibility of the stimuli and its access to consciousness. According to the

148 two-memory systems theory, we should observe the beneficial effect of applying the

149 DOP under conditions of non-conscious processing, since (i) the association established

150 between the sample stimulus and the specific outcome is formed via an implicit process

151 (Pavlovian associations) and (ii) the activation and maintenance of these reward

152 expectancies also depends on an implicit prospective memory system. Thus, we should

153 observe a similar magnitude of the DOP effect under subliminal or supraliminal

154 presentations of either the cue stimulus or the outcome. 
Regarding to the NOP condition, we propose two possible hypotheses. 1) If, as

156 the two-memory systems theory indicated, explicit processing is required to maintain

157 active the memory of the cue during the delay, performance should improve (faster

158 and/or more accurate) with the supraliminal condition as compared to the subliminal

159 one. This is due, among other factors, to the superior encoding of supraliminal

160 visuospatial information (Salti et al., 2015). 2) By contrast, if, as Mok (2012)

161 suggested, this retrospective process can be spontaneously engaged (without a

162 deliberate intention and depending on the default brain network), then it is possible that

163 the subliminal processing of the cue would be enough to activate it. If this was the case,

164 then performance should be equivalent in both conditions (subliminal vs. supraliminal).

165 Finally, according to Savage and colleagues, since the NOP does not depend on the

166 expectancy of the outcomes and is activated by retrospective memory, responses in the

167 delayed visual recognition task should be the same regardless of how the outcomes are

168 presented (subliminally vs. supraliminally) in the NOP condition.

The main aim of these experiments was to test whether the DOP would still improve visual recognition memory in healthy adults with subliminal (unconscious) presentations applied either to the outcomes (Experiment 1A) or to the sample stimuli compare subliminal and supraliminal conditions in both experiments.

175 Method

Participants. In the two experiments included here, participants were undergraduates from the University of Almería (Spain). We conducted a priori power analysis with the G*Power software 3.1.9.2 (Faul, Erdfelder, Lang, \& Buchner, 2007) to determine the minimum required sample size to detect both main effects and 
180 interactions (between-subjects factors). With an alpha $=.05$ and power $=.80$, the analysis revealed that thirty-six participants were required to detect a small-medium effect size $(\mathrm{d}=0.44)$. The effect size expected is based on previous studies concerning to the DOP in healthy adults (e.g., Plaza et al., 2018).

Forty-four participants (ranging in age from 18 to 38 years, $M=20.9, \mathrm{SD}=4.9$ ) and forty-six participants (ranging in age from 18 to 36 years, $M=20.8, S D=3.2$ ) volunteered in experiments $1 \mathrm{~A}$ and $1 \mathrm{~B}$, respectively. These opportunistic samples included 10 males and 34 females (Experiment 1A) and 14 males and 32 females (Experiment 1B). Written informed consent was obtained from all participants. The study was approved by the University of Almería Human Research Ethics Committee and was conducted in accordance with the Declaration of Helsinki. Participants reported normal or corrected-to-normal vision and were naïve with respect to the purposes of the experiment. They received extra course credit for their participation and the chance to win one of the prizes that were raffled off at the end of the study. colour monitor (15-inch VGA monitor) of an IBM-compatible computer. The E-prime software (Psychology Software Tools Inc., 2012) controlled the stimulus presentation as well as the collection of the participant's responses (latency and accuracy data). Participants were tested individually in quiet rooms with identical sound and lighting conditions. The stimuli were six white circular shapes with shaded sectors (see Figure 1 depicting the stimulus sequence) designed by one of the authors (I.C.) with the AutoCAD software (Autodesk, 2010). Four of them were presented as initial cue stimuli and the rest as comparison stimuli. The size of the shapes was $3^{\circ} \times 3^{\circ}$ of visual angle and could be displayed either individually at the centre of the screen (sample stimulus), 
or in a $2 \times 3$ grid (comparison stimuli). Four reinforces (a pen drive, a five-euro bill, a key ring or a set of four pens) were used in the experiment and they were raffled off at

207 the end of the study. Pictures of these prizes were used as outcomes. They appeared at

208 the center of the screen along with both a congratulation phrase ("very well", "well

209 done", "congratulations" or "very good") and the phrase "you may win a" followed by

210 the name of a reinforcer, after a correct choice. The phrases were in Courier New, size

21112 and in white colour.

212

213

214

215

216

217

218

Figure 1. Stimulus sequence (from left to right) used in Experiment 1A.

\section{Procedure}

As a first step, we conducted two pilot studies to make sure that participants

were not able to perceive the stimuli consciously. In the first one $(\mathrm{N}=62)$ we tested the

following parameters: (i) stimulus presentation time $(17 \mathrm{~ms}, 33 \mathrm{~ms}, 50 \mathrm{~ms}, 67 \mathrm{~ms}$ or 80

ms); (ii) pattern mask presentation time (100 ms or $200 \mathrm{~ms}$ ), and (iii) type of pattern 
230 outcomes, were displayed for $17 \mathrm{~ms}$, with a double pattern mask (before and after the

231 stimulus) during $200 \mathrm{~ms}$, all participants informed that they had seen no stimulus. With

23233 or $50 \mathrm{~ms}$ and the same type of mask, most of the participants reported that they had

233 seen some of them. Finally, when the stimuli appeared for 67 or $80 \mathrm{~ms}$, all participants

234 reported full conscious processing. In the second pilot study, we designed a decision

235 task following the stimulus parameters. Eight circular sample stimuli and eight square

236 sample stimuli were presented subliminally during $17 \mathrm{~ms}$, with two pattern masks

237 appearing before and after each of them for $200 \mathrm{~ms}$. Each stimulus appeared twice, so

238 the total number of trials was 32. For each trial, participants $(\mathrm{N}=42)$ had to decide

239 whether they had seen a circular or a square shape by pressing the " 1 " or " 2 " keys on

240 the keyboard. Participants knew in advance that there was the same number of circular

241 and square shapes. The results revealed a performance at chance for all participants

242 demonstrating no indication of conscious processing of the stimuli.

243 For the final experiments, participants performed a delayed matching to sample

244 task (DMTS). As in previous studies (e.g., López-Crespo et al., 2009; Plaza et al.,

245 2012), a variable delay of 5 and 25 seconds was interposed between the offset of the

246 sample stimulus and the onset of the comparison stimuli in both experiments. The task

247 lasted approximately 20 minutes.

248 In Experiment 1A, each participant received the same verbal instructions, also

249 written on the screen: "First, a central fixation point will appear. Then, it will be

250 replaced by a circular shape presented for a short time. You must pay attention because,

251 after a variable delay, you will have to identify the shape that you have just seen out of

252 six different options by clicking on it with the mouse. When you are ready, please press

253 the space bar to begin". In addition, all of them were informed that (i) a masked

254 outcome would appear after their responses (see Figure 1), (ii) even when they could 
not to see it, the outcome for the correct responses included a picture of one of four prizes along with both a congratulation phrase and the phrase 'You may win a (the name of the specific prize)" whereas incorrect choices would be followed by a blank screen; (ii) the four prizes would be raffled off at the end of the study; and, (iii) the more accurate their responses were, the more tickets they would win for the raffle with higher chances of winning one of the prizes. Finally, participants were also asked to choose one of the comparison shapes as quickly as possible.

Each trial began with a fixation cross presented for $1000 \mathrm{~ms}$ (see Figure 1). After a blank brief period of $500 \mathrm{~ms}$, a visual sample stimulus was displayed for $1000 \mathrm{~ms}$ followed by a variable delay of $5000 \mathrm{~ms}$ or $25000 \mathrm{~ms}$ with a blank screen. Then, six comparison stimuli (the sample stimulus plus five distractor shapes) appeared and remained on the screen until the participants responded by clicking with the left mouse button on one of the shapes, or 10 seconds were elapsed, whichever occurred first. The position of the correct sample stimulus among the comparison stimuli was counterbalanced. When the response was correct, the specific outcome was presented during $17 \mathrm{~ms}$ (subliminal condition) or $80 \mathrm{~ms}$ (supraliminal condition), right in between two masked patterns that appeared for $200 \mathrm{~ms}$ before and after the outcome. When the response was incorrect, the screen remained blank during the same time used for the outcome presentation (17 or $80 \mathrm{~ms}$ ). The trial was also scored as incorrect if the participant did not emit any response in $10 \mathrm{~s}$.

Participants were randomly assigned to one of the two experimental outcomes conditions, differential (DOP; $\mathrm{N}=21$ ) and non-differential (NOP; $\mathrm{N}=23$ ). In the DOP condition, each to-be-remembered stimulus was associated with one specific outcome so that the correct response to a particular stimulus was always followed by its own consequence. In the NOP condition, each correct response was followed by the random 
280 presentation of one of four possible outcomes. For 26 participants (12 in the DOP and

28114 in the NOP condition), outcomes were presented subliminally, being supraliminal for

282 the remaining participants $(\mathrm{N}=18 ; 9$ in the DOP and 9 in the NOP condition). All of

283 them performed four practice trials followed by 72 training trials, grouped in six blocks

284 of 12 trials each. The order of the blocks and the position of the correct comparison

285 stimulus on the screen were counterbalanced across participants. At the end of the

286 experiment, each participant had to report whether they had perceived any shape in the

287 masked outcome screen or not. They were not told that they would be tested later. Two

288 participants, one in the NOP condition and one in the DOP condition, reported they had

289 perceived an image. Although none of them knew the identity of the outcome, their data

290 were not included in the statistical analysis.

291 In Experiment 1B, the procedure was similar to that used in the Experiment 1A

292 with a few changes: i) The sample stimulus, instead of the outcome, was presented

293 either subliminally (17 ms) or supraliminally ( $80 \mathrm{~ms}$ ), interposed between two masked

294 patterns that appeared for $200 \mathrm{~ms}$ (before and after the sample stimulus). ii) The number

295 of sample stimuli and reinforcers was reduced from four to two. Previous pilot tests

296 conducted in our lab revealed that when the sample stimulus was presented subliminally

297 (instead of the outcomes), the task difficult substantially increased with participants

298 performing close to chance. Therefore, we reduced the number of the sample stimuli to

299 make the task easier. iii) Instructions were modified so that participants were asked to

300 choose one comparison shape as quickly as possible, even if they had not seen any

301 shape before the presentation of the choice stimulus. iv) Participants were also informed

302 that when their responses were correct, they would see a picture of a prize along with

303 both a congratulation phrase and the phrase 'You may win a (the name of that specific

304 prize)'; by contrast, the screen would remain blank for several seconds after their 
305 incorrect responses. v) The outcomes were displayed on screen for $1500 \mathrm{~ms}$ after the 306 correct responses.

307 As in Experiment 1A, participants were randomly assigned to one of the two

308 experimental outcomes conditions, differential (DOP; $\mathrm{N}=24$ ) and non-differential

309 (NOP; $\mathrm{N}=22$ ). For 26 participants (14 in the DOP and 12 in the NOP condition), the

310 sample stimuli were presented subliminally; their presentation was supraliminal for the

311 remaining participants $(\mathrm{N}=20 ; 10$ in the DOP and 10 in the NOP condition).

312 At the end of the experiment, as in the Experiment 1A, participants had to report

313 whether they had noticed any shape in the masked sample stimulus screen or not. None

314 of them reported having perceived an image.

\section{Statistical analysis}

316 Percentages of correct responses and median correct response times for each

317 participant were submitted to a $2 \times 2 \times 2$ mixed ANOVA with Outcomes (DOP and

318 NOP) and Type of presentation (subliminal and supraliminal) as the between-

319 participants factors and Delay ( $5 \mathrm{~s}$ and $25 \mathrm{~s}$ ) as the within-participants factor. The

320 statistical significance level was set at $\mathrm{p} \leq .05$. Normality of data was checked using

321 Kolmogorov-Smirnov test, and homogeneity of variance was tested using Levene's test.

322 Results showed the normal distribution of data and the homogeneity of variance in all

323 variables.

\section{Results}

325 Accuracy data. In Experiment 1A, the results showed that participants were more

326 accurate in the DOP (71\% correct responses) than in the NOP condition (54\% correct

327 responses), [main effect of Outcomes, $F(1,40)=15.11, p<0.001, \eta_{p}{ }^{2}=0.27$ ]. The

328 comparison between the subliminal and non-subliminal conditions did not show

329 statistically significant differences $\left[\mathrm{F}(1,40)=2.99, \mathrm{p}=0.091, \eta_{\mathrm{p}}{ }^{2}=.07\right]$ (see Figure 2, 
330 panel A). For theoretical reasons, despite the Outcomes x Type of presentation

331 interaction not reaching significance $\left[\mathrm{F}(1,40)=1.10, \mathrm{p}=0.30, \eta_{\mathrm{p}}{ }^{2}=.02\right]$, we nevertheless

332 tested whether the DOP showed the expected benefits in the subliminal group. The

333 results revealed that accuracy was better in the DOP condition (72\% correct responses)

334 than in the NOP condition (60\% correct responses), [main effect of Outcomes, F

$\left.335(1,24)=5.36, \mathrm{p}=0.029, \eta_{\mathrm{p}}^{2}=0.18\right]$. Similarly, in the supraliminal group, accuracy was

336 better in the DOP condition (69\% correct responses) than in the NOP condition (48\%

337 correct responses) [main effect of Outcomes, $\left.F(1,16)=9.17, p=0.008, \eta_{p} 2=0.36\right]$. No

338 main effect of Delay was found $\left[\mathrm{F}(1,40)=3.36, \mathrm{p}=0.08, \eta_{\mathrm{p}} 2=0.07\right]$. No other variables

339 nor interactions reached significance. ( $\mathrm{ps}>0.05$ ).

340 As mentioned earlier, the benefits of the DOP did not change depending on the

341 type of presentation, but the mean accuracy data showed that these benefits were nearly

342 twice as large in the supraliminal as in the subliminal condition. Subsequently we tested

343 the equality of these outcomes conditions between the subliminal and supraliminal

344 groups. The estimated Bayes factors $\left(\mathrm{BF}_{01}\right)$ suggested that the differences in masking

345 for the DOP group were 3:1 times in favour of the Null Hypothesis, providing

346 substantial evidence for the equality of the group means (Jarosz \& Wiley, 2014). In the

347 NOP group, there were no signs of improvement of learning due to consciousness with

348 even a 0.7:1 tendency (albeit very weak) in favour of an unexpected alternative

349 hypothesis that would see an increase in accuracy in subliminal rather than in the

350 supraliminal group (See Figure 2). 


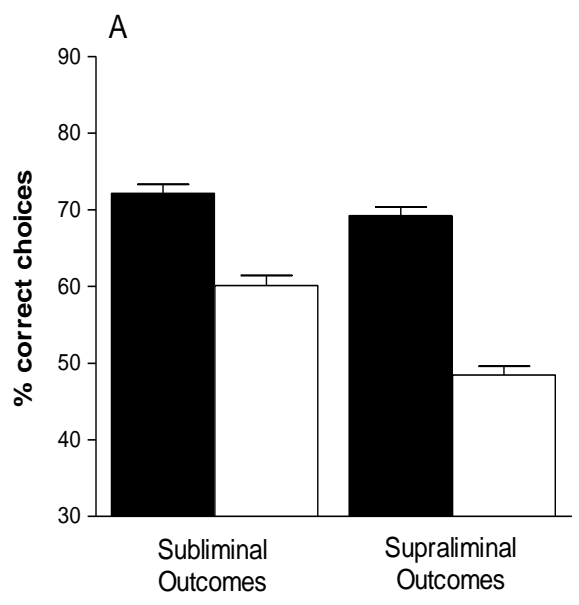

B

DOP

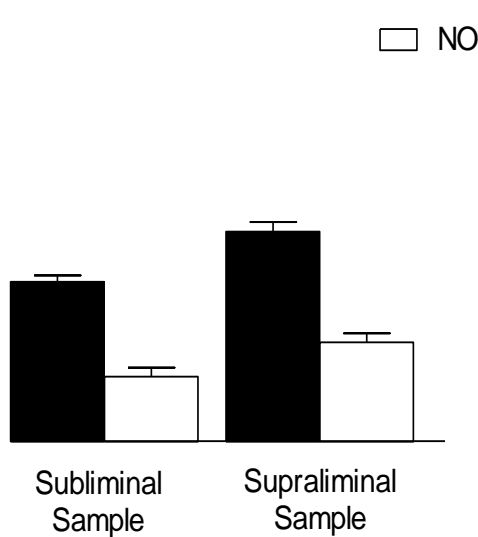

352

353 Figure 2. Mean percentage of correct responses obtained by participants in experiments

354 1A (panel A) and 1B (panel B) as a function of Outcomes (differential -DOP- vs. nondifferential -NOP-) and Type of presentation (subliminal vs. supraliminal). Error bars represent the standard deviations.

In Experiment 1B, the analysis of the correct responses also revealed that those participants assigned to the DOP condition performed the task better than those who received non-differential outcomes after their correct responses (53\% and $40 \%$ accuracy for the DOP and NOP conditions, respectively) [main effect of Outcomes $\left.\mathrm{F}(1,42)=14.64, \mathrm{p}<0.001, \eta_{\mathrm{p}}^{2}=0.26\right]$. As in the previous experiment, there were not differences between both types of presentation (subliminal vs. supraliminal; $44 \%$ vs. $49 \%$ correct responses for both conditions), $\left[\mathrm{F}(1,42)=2.45, \mathrm{p}=0.13 \eta_{\mathrm{p}}{ }^{2}=0.06\right]$ (see

364 Figure 2, panel B). Similarly to Experiment 1, for theoretical reasons we tested whether 365 the DOP showed the expected benefits in the subliminal group (50\% and $38 \%$ correct 366 responses in the DOP and NOP conditions, respectively) $\left[\mathrm{F}(1,24)=8.62, \mathrm{p}=0.007, \eta_{\mathrm{p}}{ }^{2}\right.$

$367=0.26]$. The same effect was found when analysing data from the supraliminal group 368 (56\% and $42 \%$ correct responses in the DOP and NOP conditions, respectively) [F 
$\left.369(1,24)=6.13, p=0.02, \eta_{p} 2=0.254\right]$. No main effect of Delay was found $[F(1,42)=3.36$,

$\left.370 \mathrm{p}=0.07, \eta_{\mathrm{p}} 2=0.07\right]$, nor any interaction between the three main factors $(\mathrm{ps}>0.05)$.

371 Finally, the estimated Bayes factors $\left(\mathrm{BF}_{01}\right)$ suggested that the effect of the type of

372 presentation was in favour of the null hypothesis 3:1 times for the NOP group and 2:1

373 for the DOP group confirming the absence of an impact due to consciousness on the

374 different types of outcomes.

375 Latency data. The analysis of latency data from both experiments only showed 376 a significant effect of Delay $\left[\mathrm{F}_{1 \mathrm{~A}}(1,40)=12.48, \mathrm{p}<0.01, \eta_{\mathrm{p}}^{2}=0.24 ; \mathrm{F}_{1 \mathrm{~B}}(1,42)=11.48\right.$,

$\left.377 \mathrm{p}<0.01, \eta_{\mathrm{p}}{ }^{2}=0.21\right]$ indicating that participant's correct responses were faster in the short

378 than in the long delay (3117 ms vs. $3380 \mathrm{~ms}$ and $4035 \mathrm{~ms} v \mathrm{ss} .3772 \mathrm{~ms}$ for both delays in

379 experiments $1 \mathrm{~A}$ and $1 \mathrm{~B}$, respectively). No other effects, nor their interactions, were

380 statistically significant (ps>0.05). Table 1 shows the mean correct RTs in the task as a

381 function of Outcomes, Type of presentation and Delay.

382 Table 1. Median correct response times (in milliseconds) obtained by participants in

383 experiments $1 \mathrm{~A}$ and $1 \mathrm{~B}$ as a function of Delay (5000 ms -short- vs. $25000 \mathrm{~ms}$-long-)

384 Outcomes (differential -DOP- vs. non-differential-NOP-) and Type of presentation

385 (subliminal vs. supraliminal). The values in parenthesis are the standard error of the 386 mean.

\begin{tabular}{clclc}
\hline & DOP & NOP & DOP & NOP \\
\hline Experiment 1A & \multicolumn{2}{c}{ Subliminal outcomes } & \multicolumn{2}{c}{ Supraliminal outcomes } \\
Short-delay & 3353.42 & 3212.11 & 2949.00 & 2952.06 \\
& $(257.44)$ & $(238.34)$ & $(297.26)$ & $(297.26)$ \\
Long-delay & 3669.58 & 3420.82 & 3133.00 & 3293.61 \\
& $(270.10)$ & $(250.06)$ & $(311.88)$ & $(311.88)$ \\
Experiment $1 B$ & Subliminal samples & \multicolumn{2}{c}{ Supraliminal samples }
\end{tabular}




$\begin{array}{lllll}\text { Short-delay } & 4053.93 & 3864.54 & 3436.25 & 3734.00 \\ & (270.59) & (292.27) & (252.05) & (252.05) \\ \text { Long-delay } & 4424.14 & 4175.38 & 3373.35 & 4167.05 \\ & (273.21) & (295.10) & (246.09) & (246.09)\end{array}$

387

388

389

390

391

392

393

394

395

396

397

398

399

400

401

402

403

404

405

406

407

\section{Discussion}

One relevant question we might ask is whether being aware of the specific consequences of our actions is a necessary condition for them to have beneficial effects in cognition (as demonstrated by the DOP effect). The two-memory systems theory (e.g., Savage \& Ramos, 2009) would claim this not be the case, because expectancies of the specific outcomes are implicitly formed via classical conditioning associations (i.e., sample stimulus-outcome). After several pairings, the presentation of the sample stimulus would activate the representation of its own and unique outcome and this can be used to make the correct choice. This activation is meant to be automatic and nonintentional, both characteristics of implicit memory systems. Thus, the unique expectancy of the outcome, represented in a prospective memory trace, could be implicitly formed and stay active for some time. Our findings are in agreement with this theory. DOP benefits in visual recognition memory were observed whether the specific outcomes were subliminal or supraliminal (Experiment 1A). Similar results were obtained regardless of the awareness of the sample stimulus (subliminal vs. supraliminal presentation, Experiment 1B). These results clearly show that the explicit knowledge of the sample is not necessary either for it to create and activate expectancies about its unique outcome. Given that the DOP effect was evident in both experiments across all conditions, the results clearly support the idea of an implicit-prospective memory process activated when the outcomes are differentially administrated. To our 
408 knowledge, this is the first time that the DOP effect has been reported under

409

410

411

412

413

414

415

416

417

418

419

420

421

422

423

424

425

426

427

428 unconscious conditions.

Regarding the NOP, results from Experiment 1B are most relevant here. If, as suggested by the two-memory systems model (e.g., Savage \& Ramos, 2009), the presence of non-differential outcomes triggers an explicit retrospective memory process, then a supraliminal sample should have been better remembered than the subliminal one. However, performance was similar in both conditions. This fits with the idea that this type of retrospective memory is activated spontaneously (Mok, 2012) without a deliberate intention. In fact, it seems that only a subliminal encoding of the stimulus is enough to engage it. Based on this finding, we would no longer be referring to this retrospective memory as explicit (in which we are aware of the stimulus and keep it active in memory, Graf $\&$ Schacter, 1985). Rather, we think of it as the activation of an implicit representation of the stimulus that has just been presented. Nonetheless, it is possible that this still is the same retrospective memory processes proposed by Savage and colleagues (see also Mok, 2012 and Mok et al., 2009) largely based around the activity of the hippocampus. Accordingly, and contrary to previous theories assigning to the hippocampus an exclusive role in explicit memory, recent studies have found that this brain region is involved in both explicit and implicit memory (e.g., Addante, 2015). To further confirm this, future neuroimaging studies should investigate whether the neurobiological mechanisms activated by the DOP are the same whether the processing is conscious or not.

Finally, it is worth noting that in Experiment 1A, despite the lack of interaction between the outcomes and the type of stimulus presentation, there is still a marginally better performance in the NOP condition when the outcomes were subliminally presented as compared to when the presentation was supraliminal $[\mathrm{F}(1,21)=4.02$, 
$\left.433 \mathrm{p}=0.056, \eta_{\mathrm{p}}^{2}=.16\right]$. This effect could be explained in two different ways: (i) the

434 supraliminal reward may interfere with retrospective working memory process

435 (Zedelius, Veling, \& Aarts, 2011; Zedelius et al., 2014) or (ii) the increase in conscious

436 working memory load (having to remember the sample stimuli plus the four explicit

437 outcomes) may have a detrimental impact on performance (Vogel, Woodman, \& Luck,

438 2001; Awh, Barton, \& Vogel, 2007). Further research is needed to clarify this issue.

439 To conclude, the present results are important to understand the cognitive

440 mechanisms underlying the benefits observed in the human version of the DOP. In fact,

441 we demonstrated that these beneficial effects depend on implicit mechanisms, as

442 proposed by the two-memory systems, and can be observed regardless the awareness of

443 either the sample stimulus or its associated outcome. Furthermore, we consider that

444 these findings throw some light on how we process information in situations in which

445 we know (consciously or not) the specific consequences of our choices. We think that,

446 from an evolutionary perspective, being able to predict these consequences has been so

447 crucial for survival that its benefits are observed even when they are unconscious. Thus,

448 as soon as a stimulus-unique outcome association can be established, the way the brain

449 processes the information seems to change to an implicit-prospective manner; helping

450 optimizing the functioning of cognitive processes involved in memory and learning.

451 This research has strong implications when applying the differential outcomes

452 methodology at different stages of human brain development, in patients who have

453 diminished conscious processing for a variety of reasons (such as brain injury or

454 neurodegenerative impairments), or with disabilities specifically affecting explicit

455 memory and/or executive functions (e.g., patients diagnosed with Alzheimer's disease,

456 Cushing's syndrome or schizophrenia). Similarly, because we have shown that explicit

457 knowledge of consequences would not be necessary for the DOP to improve memory 
458

459

460

461

462

463

464

465

466

467

468

469

470

471

472

473

474

475

476

477

478

479

480

481

482

483

484

and learning processes, our results further support its use as a powerful learning tool in educational contexts from early childhood to older people with or without cognitive deficits.

\section{Conflict of interest}

The authors report no conflicts of interest.

\section{Acknowledgements}

This research was supported by Grant PSI2015-65248-P from the Spanish Ministry of Economy and Competitiveness, co-funded by ERDF (FEDER) funds. IC was supported by a pre-doctoral grant by the Ministry of Education, Culture and Sport (FPU2014-03091).

(1)

References

Addante, R. J. (2015). A critical role of the human hippocampus in an electrophysiological measure of implicit memory. NeuroImage, 109, 515-528. http://dx.doi.org/10.1016/j.neuroimage.2014.12.069

Autodesk software (2010). AutoCAD (Computer Software). Autodesk products.

Awh, E., Barton, B., \& Vogel, E. K. (2007). Visual working memory represents a fixed number of items regardless of complexity. Psychological Science, 18, 622-628. http://dx.doi.org/ 10.1111/j.1467-9280.2007.01949.x

Breitmeyer, B. G., \& Öğmen, H. (2006). Oxford psychology series. Visual masking: Time slices through conscious and unconscious vision (2nd ed.). New York, NY, US: Oxford University Press. http://dx.doi.org/10.1093/acprof:oso/9780198530671.001.0001 
485 Carmona, I., Vivas, A. B., \& Estévez, A. F. (2019). Differential outcomes training

486 ameliorates visual memory impairments in patients with Alzheimer's disease: A

487 pilot study. Frontiers in Psychology, 9:2671.

$488 \quad$ https://doi.org/103389/fpsyg.2018.02671

489 Dehaene, S., Changeux, J. P., Naccache, L., Sackur, J., \& Sergent, C. (2006).

490 Conscious, preconscious, and subliminal processing: a testable taxonomy. Trends

$491 \quad$ in Cognitive Sciences. https://doi.org/10.1016/j.tics.2006.03.007

492 Easton, A. (2004). Differential reward outcome learning in adult humans. Behavioural

493 Brain Research, 154, 165-169. http://dx.doi.org/10.1016/j.bbr.2004.02.023

494 Esteban, L., Plaza, V., López-Crespo, G., Vivas, A. B, \& Estévez, A. F. (2014).

495 Differential outcomes training improves face recognition memory in children and

496 in adults with Down syndrome. Research in Developmental Disabilities, 35(6),

497 1384-392. http://dx.doi.org/10.1016/j.ridd.2014.03.031.

498 Esteban L., Vivas A. B., Fuentes L. J., \& Estévez A. F. (2015). Spatial working

499 memory is enhanced in children by differential outcomes. Scientific Reports, 5,

$500 \quad$ 17112. http://dx.doi.org/10.1038/srep17112

501 Estévez, A. F., Vivas, A. B., Alonso, D., Marí-Beffa, P., Fuentes, L. J., \& Overmier, J. B. (2007). Enhancing challenged students' recognition of mathematical relations through differential outcomes training. The Quarterly Journal of Experimental Psychology, 60 (4), 571-580. http://dx.doi.org/10.1080/17470210600820039

505 Estévez A. F., Fuentes L. J., Overmier J. B., \& González C. (2003). Differential 506 outcomes effect in children and adults with Down syndrome. American Journal of Mental Retardation, 108, 108-116. http://dx.doi.org/10.1352/0895-8017 
509 Faul, F., Erdfelder, E., Lang, A. G., \& Buchner, A. (2007). G*Power: a flexible

510 statistical power analysis program for the social, behavioural, and biomedical sciences. Behavioural Research Methods, 39, 175-191. http://dx.doi.org/10.3758/BF0319 3146

513 Graf, P., \& Schacter, D. L. (1985). Implicit and explicit memory for new associations in normal and amnesic subjects. Journal of Experimental Psychology: Learning, Memory, and Cognition, 11(3), 501-518. http://dx.doi.org/10.1037/02787393.11.3.501

Hochhalter A. K., Sweeney W. A., Bakke B. L., Holub R. J., \& Overmier J. B. (2000). Improving face recognition in Alcohol Dementia. Clinical Gerontology, 22, 3-18. http://dx.doi.org/ 10.1300/j018v22n02_02.

Jarosz, A. F., \& Wiley, J. (2014). What are the odds? A practical guide to computing and reporting Bayes factors. The Journal of Problem Solving, 7(1), 2. http://dx.doi.org/ 10.7771/1932-6246.1167

Joseph, B., Overmier, J. B., \& Thompson, T. (1997). Food- and nonfood-related

López-Crespo, G., Plaza, V., Fuentes, L. J., \& Estévez, A. F. (2009). Improvement of age-related memory deficits by differential outcomes. International Psychogeriatrics, 21, 503-510. http://dx.doi.org/ 10.1017/s1041610209008576

Maki, P., Overmier, J. B., Delos, S., \& Gutmann, A. J. (1995). Expectancies as factors influencing conditional discrimination performance of children. The Psychological Record, 45, 45-71.

Martínez L., Estévez A. F., Fuentes L. J., \& Overmier J. B. (2009). Improving conditional discrimination learning and memory in five-year-old children: DOE 

using different types of reinforcement. The Quarterly Journal of Experimental Psychology, 62, 1617-1630. http://dx.doi.org/10.1080/17470210802557827

Martínez L., Marí-Beffa P., Roldán-Tapia D., Ramos-Lizana J., Fuentes L. J., \& Estévez A. F. (2012). Training with differential outcomes enhances discriminative learning and visuospatial recognition memory in children born prematurely. Research in Developmental Disabilities, 33, 76-84. http://dx.doi.org/10.1016/j.ridd.2011.08.022

Miller O. T., Waugh K. M., \& Chambers K. (2002). Differential outcomes effect: increased accuracy in adults learning Kanji with stimulus specific rewards. Psychological Record, 52, 315-324. http://dx.doi.org/ 10.1007/BF03395433

Mok L. W., \& Overmier J. B. (2007). The differential outcomes effect in normal human adults using a concurrent-task within-subjects design and sensory outcomes. Psychological Record, 57, 187-200. http://dx.doi.org/10.1007/BF03395571

Mok, L. W., Thomas, K. M., Lungu, O. V., \& Overmier, J. B. (2009). Neural correlates of cue-unique outcome expectations under differential outcomes training: An fMRI study. Brain Research, 1265, 111-127. http://dx.doi.org/10.1016/j.brainres.2008.12.072

Mok, L. (2012). Short-term retrospective versus prospective memory processing as emergent properties of the mind and brain: human fMRI evidence. Neuroscience, 13; 226:236-52. doi.org/ 10.1016/j.neuroscience.2012.09.005

Molina, M., Plaza, V., Fuentes, L. J., \& Estévez, A. F. (2015). The Differential Outcomes Procedure Enhances Adherence to Treatment: A Simulated Study with Healthy Adults. Frontiers in Psychology, 6, 1780. http://dx.doi.org/10.3389/fpsyg.2015.01780 
558 Overmier, J. B., Savage, L. M., \& Sweeney, W. A. (1999). Behavioral and

559

560

561

562

563

564

565

566

567

568

569

570

571

572

573

574

575

576

577

578

579

580

581

582 pharmacological analyses of memory: New behavioural options for remediation. In M. Haug, \& R. E. Whalen (Eds.), Animal models of human emotion and cognition (pp. 231-245). Washington, DC: American Psychological Association.

Plaza V., Estévez A. F., López-Crespo G., \& Fuentes L. J. (2011). Enhancing recognition memory in adults through differential outcomes. Acta Psychologica, 136, 129-136. http://dx.doi.org/ 10.1016/j.actpsy.2010.11.001

Plaza, V., Molina, M., Fuentes, L. J., \& Estévez, A. F. (2018). Learning and Recall of Medical Treatment-Related Information in Older Adults Using the Differential Outcomes Procedure. Frontiers in Psychology, 9: 157. http://dx.doi.org/ 10.3389/fpsyg.2018.00157

Plaza, V., López-Crespo, G., Antúnez, C., Fuentes, L. J., \& Estévez, A. F. (2012). Improving delayed face recognition in Alzheimer's disease by differential outcomes. Neuropsychology, 4, 483-489. http://dx.doi.org/ 10.1037/a0028485

Psychology Software Tools (2012). E-Prime (Computer Software). Pittsburgh, PA: Psychology Software Tools.

Salti, M., Monto, S., Charles, L., King, J., Parkkonen, L., \& Dehaene, S. (2015). Distinct cortical codes and temporal dynamics for conscious and unconscious percepts. eLife, 4:e05652. http://dx.doi.org/ 10.7554/eLife.05652

Savage, L. M., Buzzetti, R. A., \& Ramirez, L. R. (2004). The effects of hippocampal lesions on learning, memory, and reward expectancies. Neurobiology of Learning and Memory, 82, 109-119. http://dx.doi.org/10.1016/j.nlm.2004.05.002

Savage, L. M, Pitkin, S. R., \& Careri, J. M. (1999). Memory enhancement in aged rats: The differential outcomes effect. Developmental Psychobiology, 35, 318-327. doi: http://dx.doi.org/ 10.1007/BF02734258 
583 Savage, L. M., \& Ramos, R. L. (2009). Reward expectation alters learning and memory:

584 The impact of the amygdala on appetitive-driven behaviors. Behavioral Brain

$585 \quad$ Research, 198, 1-12. http://dx.doi.org/ 10.1016/j.bbr.2008.10.028

586 Savage, L. M. (2001). In search of the neurobiological underpinnings of the differential $587 \quad$ outcomes effect. Integrative Physiological and Behavioral Science, 36, 182-195. $588 \quad$ http://dx.doi.org/ 10.1007/BF02734092.

589 Vogel, E. K., Woodman, G. F., \& Luck, S. J. (2001). Storage of features, conjunctions, 590 and objects in visual working memory. Journal of Experimental Psychology:

$591 \quad$ Human Perception and Performance, 27 1, 92- 114.

$592 \quad$ http://dx.doi.org/10.1037/0096-1523.27.1.92

593 Zedelius, C., Veling, H., \& Aarts, H. (2011). Boosting or choking-How conscious and 594 unconscious reward processing modulate the active maintenance of goal-relevant 595 information. Consciousness and Cognition, 20, 355-362. http://dx.doi.org/

$596 \quad$ 10.1016/j.concog.2010.05.001

597 Zedelius, C. M., Veling, H., Custers, R., Bijleveld, E., Chiew, K.S., \& Aarts, H. (2014).

598 A new perspective on human reward research: how consciously and

599 unconsciously perceived reward information influences performance. Cognitive,

$600 \quad$ Affective \& Behavioural Neuroscience, 14 2, 493-508.

$601 \quad$ https//dx.doi.org/10.3758/s13415-013-0241-z 